\title{
PENANAMAN NILAI KEISLAMAN PADA ANAK DHUAFA DI PAUD INSAN CERDAS KOTA BEKASI
}

\author{
Khusniyati Masykuroh ${ }^{1}$ \\ ${ }^{1}$ Universitas Muhammadiyah Prof. DR. HAMKA \\ Email : khusniyati.masykuroh@uhamka.ac.id,
}

\begin{abstract}
This study aims to find out an overview of the instilling of Islamic values on disadvantaged children, to find out the methods used in instilling Islamic values, to find out the obstacles and supports in instilling Islamic values, and to know the impact of instilling Islamic values for disadvantaged children at PAUD Insan Cerdas, Kota Bekasi. The method used in this study is a qualitative research by collecting data through observation, interviews, and documentation. Data analysis was carried out through three lines of data reduction, data presentation, and conclusion. As for the validity of the data, triangulation of various sources is used. The results of the study show that: 1) Instilling Islamic values on disadvantaged children at PAUD Insan Cerdas through four main components, they are: the introduction of faith, the practice of worship, morality, and the introduction of reading and short surah of the Qur'an; 2) The methods of instilling Islamic values used are storytelling, singing, playing, demonstrating, practicing, and answering question 3) The obstacles faced in instilling Islamic values are the parents background who had low education and low knowledge of Islam. While for the supports are the 'Insan Cerdas Foundation' and donors who care not only about children's education through Islamic curriculum programs, but also provide religious education for parents so they can synergize in instilling Islamic values at home and at school; 4) The impact of instilling Islamic values on disadvantaged children can be seen from the changes of their behavior : knowing Allah through their creations, behaving and saying well, helping each other and loving, being able to practice worship movements such as ablution, prayer, reading prayers, Hajj rituals, and knowing how to read and memorize short surah of Qur'an.
\end{abstract}

Keywords: Islamic values, disadvantaged children.

\begin{abstract}
ABSTRAK
Penelitian ini bertujuan untuk mengetahui gambaran mengenai penanaman nilai-nilai keislaman pada anak dhuafa, untuk mengetahui metode yang digunakan dalam penanaman nilai-nilai keislaman pada anak dhuafa, untuk mengetahui hambatan dan pendukung dalam penanaman nilai-nilai keislaman pada anak dhuafa, dan untuk mengetahui dampak penanaman nilai-nilai keislaman pada anak dhuafa di PAUD Insan Cerdas, Kota Bekasi. Metode yang digunakan adalah metode penelitian kualitatif dengan pengumpulan data melalui pengamatan, wawancara, dan dokumentasi. Peneliti sebagai insrumen utama dalam penelitian menggunakan pedoman observasi, pedoman wawancara, dan pedoman dokumentasi. Analisis data dilakukan melalui tiga jalur reduksi data, penyajian data, dan penarikan kesimpulan. Sedangkan untuk keabsahan data, digunakan triangulasi berbagai sumber. Hasil penelitian menunjukkan bahwa : 1)Penanaman nilai-nilai keislaman pada anak dhuafa di PAUD Insan Cerdas melalui empat komponen utama yaitu pengenalan aqidah, praktek ibadah, akhlak, serta pengenalan membaca dan surat pendek Alquran; 2)Metode penanaman nilai-nilai keislaman yang digunakan adalah berkisah, bernyanyi, bermain, pembiasaan, demonstrasi, praktek, dan tanya jawab; 3)Hambatan yang dihadapi dalam penanaman nilainilai keislaman adalah latar belakang orang tua murid yang semuanya adalah dhuafa berpendidikan rendah dengan tingkat pengetahuan agama yang rendah. Sedangkan untuk pendukungnya adalah Yayasan Insan Cerdas dan donatur yang peduli tidak hanya pada pendidikan anak melalui program kurikulum keislaman, namun juga memberikan pendidikan agama untuk orang tua supaya bisa bersinergi dalam menanamkan nilai keislaman di rumah dan di sekolah; 4)Dampak penanaman nilai keislaman pada anak dhuafa terlihat pada perubahan perilaku anak mengenal Allah melalui ciptaannya, bersikap dan berkata baik, saling membantu dan menyayangi, mampu praktek gerakan ibadah seperti wudhu, sholat, doa, manasik haji, serta mengenal bacaan dan surat pendek Al-quran.
\end{abstract}

Kata kunci : nilai keislaman, anak, dhuafa 


\section{Khusniyati Masykuroh. PENANAMAN NILAI KEISLAMAN PADA ANAK DHUAFA DI PAUD INSAN CERDAS KOTA BEKASI. Early Childhood Vol. 4 No. 1, Mei 2020}

PENDAHULUAN

Penanaman nilai-nilai keislaman pada anak usia dini merupakan hal yang fundamental dalam tumbuh kembang anak. Zaman terus berkembang dan kemajuan teknologi tidak bisa di hindari lagi. Bagaikan pisau bermata dua, kemajuan teknologi membawa manfaat dan juga madharat bagi manusia. Teknologi memudahkan pekerjaan manusia, namun juga bisa berakibat buruk saat manusia tidak mampu untuk mengelola kemajuan teknologi dengan bijak. Ancaman pornografi dan kekerasan di dunia maya, ujaran kebencian dan memecah belah persaudaraan di media sosial, serta kiriminalitas akibat penggunaan teknologi terkini, saat ini sudah sering kita temui. Kenakalan remaja, pergaulan bebas, penyalahgunaan narkotika dan obatobatan terlarang, mencerminkan krisis moral yang terjadi di masyarakat. Penanaman nilai-nilai keislaman diharapkan menjadi banteng pertahahanan terhadap masalah-masalah moral.

Pendidikan adalah hak setiap anak. Undang-undang Sistem Pendidikan Nasional No 20 Tahun 2003, pasal 1 ayat 14 menyatakan bahwa: "Pendidikan anak usia dini adalah suatu upaya pembinaan yang ditujukan kepada anak sejak lahir sampai dengan usia enam tahun yang dilakukan melalui pemberian rangsangan pendidikan untuk membantu pertumbuhan dan perkembangan jasmani dan rohani agar anak memiliki kesiapan dalam memasuki pendidikan lebih lanjut."

Layanan pendidikan anak usia dini terdiri dari beberapa program seperti Kelompok Bermain, Taman Kanakkanak, Taman Penitipan Anak, Satuan PAUD Sejenis, dan Pos PAUD. Orang tua bisa memilih program layanan PAUD sesuai dengan kebutuhan anak. Melalui lembaga PAUD, anak akan mendapatkan program layanan yang menstimulasi enam aspek perkembangan yaitu moral agama, kognitif, bahasa, sosial emosi, motorik, dan seni sehingga diharapkan anak akan mengalami tumbuh kembang yang optimal.

Pendidikan Anak Usia Dini merupakan salah satu bentuk penyelenggaraan pendidikan yang menitikberatkan pada peletakan dasar ke arah perkembangan fisik (koordinasi motorik halus dan kasar), kecerdasan (daya pikir, daya cipta, kecerdasan emosi, kecerdasan spiritual), sosio-emosional (sikap dan perilaku serta beragama), 


\section{Khusniyati Masykuroh. PENANAMAN NILAI KEISLAMAN PADA ANAK DHUAFA DI PAUD INSAN CERDAS KOTA BEKASI. Early Childhood Vol. 4 No. 1, Mei 2020}

bahasa dan komunikasi, sesuai dengan keunikan dan tahap-tahap perkembangan yang dilalui oleh anak usia dini (Nurani, 2013, p. 6). Karena setiap anak merupakan individu yang berbeda, sehingga tahapan pencapaian perkembangan setiap anak belum tentu dicapai pada titik-titik usia yang sama. Diperlukan bantuan dari orang dewasa dan lingkungan sekitar untuk memberikan stimulasi yang tepat untuk mengembangkan potensi anak.

Penanaman nilai-nilai keislaman pada anak usia dini hendaknya dilakukan sesuai dengan tahapan usianya. Pendidikan yang menanamkan nilai-nilai keislaman pada anak usia dini merupakan hal yang sangat fundamental dan menjadi pondasi bagi perkembangan anak pada masa berikutnya. Menurut Peraturan Menteri Pendidikan Nasional Nomer 137 Tahun 2014, Standar Tingkat Pencapaian Perkembangan Anak dalam lingkup perkembangan nilai moral dan agama untuk anak usia 5-6 tahun terdiri dari : (1) mengenal agama yang dianut, (2) mengerjakan ibadah, (3) berperilaku jujur, penolong, sopan, hormat, sportif, (4) menjaga kebersihan diri dan lingkungan, (5) mengetahui hari besar agama, (6) menghormati (toleransi) terhadap agama orang lain.
Nilai-nilai keislaman yang ditanamkan pada anak usia dini terdiri dari tiga komponen utama yaitu : (1) Aqidah. Pendidikan aqidah pada anak usia dini diberikan melalui pengenalan Allah melalui ciptaannya. Mengenal Tuhan merupakan hal yang abstrak bagi anak usia dini, oleh karena itu dalam nilai keislaman, antara lain melalui Rukun Iman dan Rukun Islam dilakukan melalui berbagai metode yang menyenangkan anak usia dini; (2) Ibadah. Pengenalan ibadah antara lain berwudhu, shalat, zakat, puasa, doa, haji, kepada anak usia dini penting untuk dilakukan. Keteladanan dan pembiasaan merupakan salah satu cara yang bisa dilakukan dalam menanamkan nilai-nilai keislaman dalam hal ibadah; (3) Akhlak.

Hadits riwayat Ibnu Majah mengatakan "Muliakan anak-anakmu, dan ajarkan budi pekerti yang baik." Islam mengajarkan orang tua untuk menanamkan nilai-nilai kebaikan kepada anaknya. Nilai-nilai akhlak yang hendaknya dikenalkan pada anak usia dini seperti jujur, sopan, santun, hemat, taat, toleransi,dan mandiri.

Ketepatan penananam nilai-nilai moral keislaman akan menjadi pondasi kokoh bagi tumbuh kembang anak usia dini di masa yang akan datang menjadi 


\section{Khusniyati Masykuroh. PENANAMAN NILAI KEISLAMAN PADA ANAK DHUAFA DI PAUD INSAN CERDAS KOTA BEKASI. Early Childhood Vol. 4 No. 1, Mei 2020}

generasi yang beriman dan berakhlak mulia. Anak diharapkan mampu mengenal Tuhan melalui ciptaan Nya, mengenal agama yang dianut, mengerjakan ibadah, dan berperilaku baik dalam bingkai Aqidah, Ibadah, dan Akhlak.

Jasuri dalam penelitiannya yang berjudul Pendidikan Agama Islam Pada Anak Usia Dini menghasilkan kesimpulan bahwa : (1) Pembelajaran pendidikan agama Islam harus disesuaikan dengan tahapan perkembangan pada anak usia dini, terutama dalam memberikan materi maupun pemilihan metodenya; (2) Materi aqidah untuk menanamkan pengenalan adanya Allah melalui ciptaan-Nya, mengenalkan kitab-kitab Allah, mengenal Nabi dan Rasul. Sedangkan materi ibadah akhlak seperti shalat berjamaah, berperilaku baik sejak dini seperti menghormati orang tua melalui pembiasaan; (3) Metode yang digunakan harus bervariasi sesuai dengan materi dan tujuan yang hendak dicapai agar pembelajaran tidak berlangsung monoton, antara lain melalui metode bercerita, karya wisata, pembiasaan, dan metode bermain sambil belajar, karena memberikan kesempatan lebih banyak kepada anak untuk mengembangkan yang dimiliki sehingga anak dapat mencapai perkembangan optimal; (4) Evaluasi pembelajaran Pendidikan Agama Islam dilaksanakan setiap kali pertemuan agar perkembangan anak dapat diketahui dan juga berfungsi untuk mengetahui berhasil atau tidaknya proses pembelajaran yang berlangsung (Jasuri, 2015).

Ety Nurhayati dengan penelitiannya dengan judul Penanaman Nilai-Nilai Keislaman Pada Anak Usia Dini Studi Kasus di RA Al-Ishlah Bobos Cirebon mendapatkan hasil bahwa bahwa : (1) Nilai-nilai keislaman yang penting ditanamkan pada anak usia dini mencakup empat komponen yaitu aqidah, ibadah, akhlak, dan membaca Al-Quran; (2) Beberapa potensi anak usia dini mencakup potensi fisik dan psikologis, sepeti fisik, otak, motivasi, atensi, memori, dan kognisi, merupakan modal dasar menerima nilai-nilai keislaman yang ditanamkan kepada mereka; (3) Metode penanaman nilai-nilai keislaman yang sudah diterapkan adalah pengenalan secara konsep/verbalistik, pembiasaan, latihan atau praktek langsung, belajar sambil bermain dengan permainan, bernyanyi, bercerita, dan hafalan; (4) Urgensi menanamkan nilai-nilai keislaman pada anak usia dini adalah 


\section{Khusniyati Masykuroh. PENANAMAN NILAI KEISLAMAN PADA ANAK DHUAFA DI PAUD INSAN CERDAS KOTA BEKASI. Early Childhood Vol. 4 No. 1, Mei 2020}

bentuk pertanggungjawaban orang tua dan pendidik terhadap amanah Allah, mempertegas fitrah keislaman yang telah Allah kepada setiap manusia, memanfaatkan masa emas anak agar hasilnya lebih efektif sebagai pondasi beragama di masa dewasa, langkah antisipatif menangkal pengaruh globalisasi, mencapai hasil efektif karena anak memiliki potensi yang dapat dikembangkan, memperteguh keyakinan pada Allah, menumbuhkan kecintaan beribadah kepada Allah semata, menumbuhkan kebiasaan berakhlak karimah yang melekat pada kepribadiannya, menumbuhkan sikap gemar membaca dan mempelajari kandungan Al-Quran, dan menjadikan sebagai pedoman hidupnya (Nurhayati, 2016).

Sedangkan penelitian yang dilakukan oleh Setiaji Raharjo dengan judul Penanaman Nilai-Nilai Agama Islam Pada Anak Usia Dini di Kelompok Bermain Aisyiah Al Husna II Pengasih Kecamatan Pengasih Kabupaten Kulonprogo menunjukkan kesimpulan bahwa : (1) Penanaman nilai-nilai agama Islam pada anak usia dini meliputi perencanaan, pelaksanaan, dan evaluasi. Dari kegiatan tersebut terlihat pencapaian perkembangan aqidah, akhlak, dan ibadah; (2) Metode penanaman nilai-nilai agama Islam pada anak usia dini yaitu dengan menggunakan metode bermain, metode pembiasaan, metode cerita, metode karya wisata, metode keteladanan, metode demonstrasi, dan tanya jawab; (3) Faktor pendukung diantara pendidik memiliki kemampuan mengajarkan agama Islam, peserta didik mampu meniru gerakan ibadah walaupun belum teratur, sekolah memiliki bukubuku Islami. Sedangkan faktor penghambat antara lain peserta didik tidak fokus dan pengelompokkan peserta didik yang dilakukan pendidik saat praktek ibadah tidak jelas (Setiaji Raharjo, 2012).

Namun rupanya tidak semua anak mempunyai kesempatan yang sama untuk menikmati layanan PAUD dengan berbagai alasan, salah satunya adalah kondisi kemiskinan keluarga. Ketidakmampuan keluarga membuat anak tidak bisa bersekolah dan mendapatkan layanan pendidikan yang berkualitas, sehingga tidak mendapatkan pembinaan yang optimal dalam mengembangkan enam aspek yaitu nilai moral dan agama, bahasa, kognitif, motorik, sosial emosi, dan seni.

Dalam Quran Surah Al-Isra ayat 26-27 diterangkan tentang kewajiban 


\section{Khusniyati Masykuroh. PENANAMAN NILAI KEISLAMAN PADA ANAK DHUAFA DI PAUD INSAN CERDAS KOTA BEKASI. Early Childhood Vol. 4 No. 1, Mei 2020}

moral seorang muslim untuk memperhatikan kaum kerabat, orang miskin dan keadaan masyarakat yang ada di sekitarnya. Kedua ayat tersebut memang berbentuk kepedulian atau kesetiakawanan sosial dalam bidang ekonomi. Hal ini merujuk pada firman Allah Swt., "Dan berikanlah kepada keluarga-keluarga yang dekat akan haknya, kepada orang miskin dan orang yang dalam perjalanan dan janganlah kamu menghambur-hamburkan (hartamu) secara boros".

Dalam Islam Allah SWT memerintahkan kita memberikan hak orang lain dari harta yang kita miliki, mulai dari kerabat dekat yang berada dalam kesulitan hidup (kemiskinan), tetangga- tetangga yang miskin dan orang-orang yang pantas menerima infaq dari harta kita, seperti ibnu sabil. Kewajiban pertama kali pada harta adalah memberikan infaq kepada kerabat terdekat yang lebih membutuhkan, agar tercipta ketentraman dalam jiwa saudara kita, dapat menumbuhkan perasaan kasih sayang dan keharmonisan antar sesama.

Dari uraian tersebut di atas, disimpulkan bahwa anak usia dini dhuafa adalah anak usia dibawah 6 tahun yang berasal dari golongan lemah dan tidak mampu, dan menjadi kewajiban muslim yang lain untuk menyantuninya. Pentingnya penanaman nilai-nilai keislaman pada anak usia dini dhuafa dilakukan karena kondisi keterbatasan keluarga, seringkali mengakibatkan anak tidak tumbuh dan berkembang secara optimal, khususnya dalam perkembangan nilai moral agama. Rasulullah SAW bersabda dalah sebuah hadits : Kaadal Fafru Ayyakuuna Kufron yang artinya "Hampir saja kefakiran menjerumuskan kekufuran." Oleh karena itu penting sebagai seorang muslim untuk menyelamatkan saudara yang lain dengan memberikan santunan baik melalui infak, zakat, wakaf, dan shadaqah untuk tetap berada di jalan Islam.

Berdasarkan observasi awal di lapangan, peneliti menemukan sebuah lembaga PAUD yang berkomitmen untuk memberikan memberikan layanan pendidikan anak usia dini untuk anakanak dari keluarga miskin secara gratis, yaitu PAUD Insan Cerdas. Lembaga PAUD ini berlokasi di perumahan Grand Cibubur, Kelurahan Jatisampurna, Kecamatan Jatisampurna, Kota Bekasi. Berlokasi di sebuah perumahan yang sebagian besar penduduknya adalah pekerja, PAUD Insan Cerdas melayani peserta didik dari keluarga miskin dan berbiaya gratis sebagai bentuk 


\section{Khusniyati Masykuroh. PENANAMAN NILAI KEISLAMAN PADA ANAK DHUAFA DI PAUD INSAN CERDAS KOTA BEKASI. Early Childhood Vol. 4 No. 1, Mei 2020}

kepedulian umat muslin terhadap keberadaan kaum dhuafa. Meskipun melayani anak-anak dhuafa yang tidak memberikan kontribusi berupa iuran pendidikan, namun PAUD Insan Cerdas tetap konsisten menanamkan nilai-nilai keislaman kepada anak-anak dhuafa di PAUD Insan Cerdas.

Tujuan penelitian ini adalah : (1) Untuk mengetahui gambaran yang sesungguhnya mengenai penanaman nilai-nilai keislaman pada anak dhuafa di PAUD Insan Cerdas, Kecamatan Jatisampurna, Kota Bekasi; (2) Untuk mengetahui metode yang digunakan dalam penanaman nilai-nilai keislaman pada anak dhuafa di PAUD Insan Cerdas; (3) Untuk mengetahui hambatan dan tantangan dalam penanaman nilai-nilai keislaman pada anak dhuafa di PAUD Insan Cerdas, Kecamatan Jatisampurna, Kota Bekasi; dan (4) Untuk mengetahui dampak penananaman nilai-nilai keislaman pada anak dhuafa di PAUD Insan Cerdas.

\section{METODE PENELITIAN}

Penelitian ini menggunakan pendekatan kualitatif. Metode penelitian kualitatif adalah metode penelitian yang digunakan untuk meneliti pada kondisi objek yang alamiah, (sebagai lawannya adalah eksperimen) dimana peneliti adalah sebagai instrumen kunci, teknik pengumpulan data dilakukan secara triangulasi (gabungan) analisis data bersifat induktif, dan hasil penelitian kualitatif lebih menekankan makna dari pada generalisasi (Sugiyono, 2016). Metode ini dipilih karena peneliti ingin melihat langsung berbagai kenyataan di lapangan yang dilakukan subjek penelitian tanpa menambah atau merubah peristiwa yang terjadi di lapangan, atau berusaha memahami perilaku subjek penelitian dari segi kerangka berpikir maupun bertindak dari subjek penelitian itu sendiri (Moleong, 2017).

Pada penelitian kualitatif menekankan pada makna dan lebih memfokuskan pada data kualitas dengan analisis kualitatifnya dan tetap memandang data kuantitas sebagai fenomena untuk mendukung analisis kualitatif bagi pemantapan makna sebagai simpulan akhir penelitian. Data dan sumber data dalam penelitian ini terdiri dari data primer dan sekunder. Data primer merupakan data yang diambil langsung peneliti kepada sumbernya, tanpa adanya perantara. Data primer diperoleh dari Kepala Sekolah, Guru, Peserta Didik, Orang Tua, dan Umat yang terlibat dalam pendidikan di 


\section{Khusniyati Masykuroh. PENANAMAN NILAI KEISLAMAN PADA ANAK DHUAFA DI PAUD INSAN CERDAS KOTA BEKASI. Early Childhood Vol. 4 No. 1, Mei 2020}

PAUD Insan Cerdas, Kelurahan Jatisampurna, Kecamatan Jatisampurna, Kota Bekasi. Sedangkan data sekunder adalah data yang diusahakan sendiri pengumpulannya oleh peneliti.

Teknik pengumpulan data melalui pengamatan, wawancara, dan dokumentasi. Data kemudian dianalisis secara bersamaan melalui reduksi data, penyajian data, dan penarikan kesimpulan (Miles \& Huberman, 1994) .

\section{HASIL DAN PEMBAHASAN}

PAUD Insan Cerdas berlokasi di perumahan Grand Cibubur, Kecamatan Jatisampunra, Kota Bekasi. PAUD berdiri sebagai bentuk kepedulian warga perumahan Grand Cibubur kepada masyarakat sekitar di luar perumahan yang mempunyai masalah mendapatkan kesempatan pendidikan, khususnya pendidikan anak usia dini yang berkualitas bagi masyarakat yang tidak mampu (dhuafa).

Bermula dari adanya rencana penutupan lembaga PAUD Al-Hikmah yang berlokasi tidak jauh dari perumahan dengan alasan pemilik yayasan akan merenovasi bangunan menjadi fungsi lain dan tidak akan melanjutkan operasional layanan pendidikan anak usia dini.
Padahal pada saat itu terdapat dua rombongan belajar yang masih terdaftar aktif sebagai peserta didik dan mayoritas berasal dari keluarga tidak mampu.

Untuk mengatasi hal tersebut, beberapa warga perumahan berhimpun untuk membantu warga masyarakat dhuafa yang tinggal disekitar perumahan Grand Cibubur untuk mendapatkan tempat belajar bagi anak-anak mereka, membantu anak-anak pra sekolah dasar untuk menyiapkan diri memasuki jenjang sekolah yang lebih tinggi, dan membantu pemerintah dalam upaya meningkatkan kualitas sumber daya manusia sejak usia dini. Sehingga terbentuk lembaga pendidikan bebas biaya dengan nama TK Insan Cerdas yang diperuntukkan anak yatim dan dhuafa yang memiliki keterbatasan akses untuk mendapatkan pendidikan setingkat sekolah Taman Kanak-Kanak.

Lembaga ini memiliki visi "Mewujudkan anak usia dini yang Cerdas, Ceria, dan Berahlak Mulia. Sedangkan misi lembaga adalah Melaksanakan Pembelajaran yang inovatif, kreatif, dan efektif, melaksanakan pendidikan anak secara optimal sesuai dengan kemampuan dan tumbuh kembang anak, mempersiapkan anak didik untuk mencapai kompetensi 
Khusniyati Masykuroh. PENANAMAN NILAI KEISLAMAN PADA ANAK DHUAFA DI PAUD INSAN CERDAS KOTA BEKASI. Early Childhood Vol. 4 No. 1, Mei 2020

dasar sebagai bekal memasuki jenjang pendidikan sekolah dasar.

Selain visi dan misi, lembaga ini juga memiliki tujuan untuk : menyediakan layanan pendidikan anak usia dini untuk anak Yatim Dhuafa, yang dikelola secara profesional tanpa memungut biaya apapun kepada orang tua siswa, membentuk dan menghasilkan anak didik yang kelak dapat menjadi insan yang cerdas, kreatif, dan berakhlaq mulia, memperluas akses dan pemerataan layanan pendidikan untuk anak usia dini bagi warga masyarakat yang tidak mampu, memberdayakan semua potensi yang ada di masyarakat untuk mendukung program pemerintah dalam penyediaan lembaga pendidikan anak usia dini untuk memberantas kebodohan dan mencerdaskan anak-anak bangsa.

\section{Penanaman Nilai-nilai Keislaman}

Penanaman nilai-nilai Islam pada anak-anak dhuafa di PAUD Insan Cerdas dalam empat komponen utama, yaitu :

a. Nilai Aqidah. Pendidikan aqidah di PAUD Insan Cerdas diberikan melalui pengenalan Allah melalui ciptaannya serta mengenal Rukun Iman dengan menggunakan metode yang menyenangkan untuk anak seperti bernyanyi, berkisah sirah nabawiah dan membacakan buku cerita, serta melihat tayangan film edukasi Islami. Selain dinyanyikan, lagulagu Islami pengenalan Allah juga disetel dengan menggunakan audio speaker, supaya anak-anak terbiasa mendengarnya. Salah satu lagu yang dinyanyikan dengan tujuan mengenalkan Allah adalah lagu berjudul "Allah Dekat" yang liriknya adalah :

Bila aku bertanya

Allah ada di mana

Dia pun berkata

Aku dekat saja

Allah senantiasa

Dekat pada hambanya

Mengabulkan doa

Siapa yang meminta

Siapa yg meminta

b. Praktek Ibadah. Pengenalan ibadah pada anak dhuafa di PAUD Insan Cerdas melalui praktek, pembiasaan dan orang dewasa menjadi model, dan dijadwalkan secara rutin sebagai program kegiatan keagamaan yang diikuti oleh semua anak. Penanaman nilai ibadah pada anak dhuafa di PAUD Insan 
Khusniyati Masykuroh. PENANAMAN NILAI KEISLAMAN PADA ANAK DHUAFA DI PAUD INSAN CERDAS KOTA BEKASI. Early Childhood Vol. 4 No. 1, Mei 2020

Cerdas melalui praktek

berwudhu, sholat berjamaah dan

berdzikir, manasik haji, dan tarhib

Ramadhan.

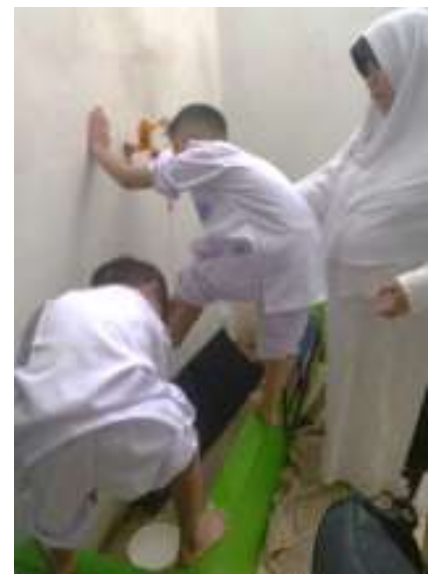

Gambar 1. Anak Praktek

Berwudhu

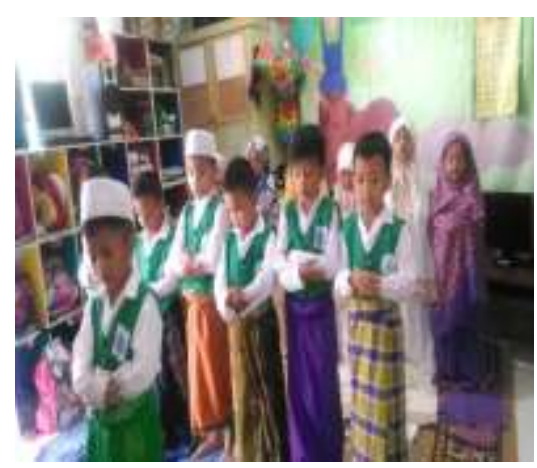

Gambar 2. Praktek Shalat

Berjamaah

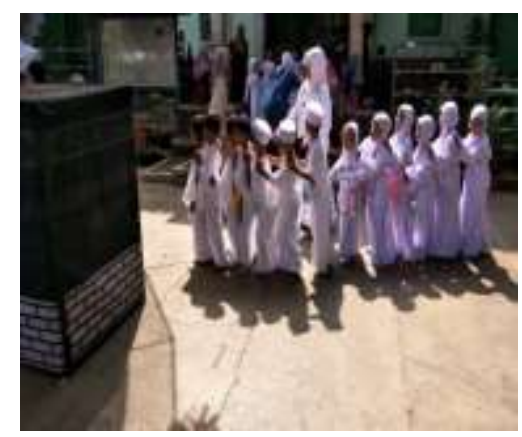

Gambar 4.

Simulasi Manasik Haji c. Akhlak. Penanaman akhlak pada anak-anak PAUD Insan Cerdas melalui pembiasaan akhlakul karimah dan keteladanan seperti mengucap dan membalas salam, mendoakan kedua orang tua, berperilaku sopan, mengucapkan terimakasih saat menerima bantuan, meminta maaf bila melakukan kesalahan, memberi maaf bila ada teman yang meminta maaf, menghormati orang tua dan guru,dan menyayangi teman, dan pembiasaan membaca doa harian dan hadits. Penanaman akhlak melalui pembiasaan, keteladanan, dan juga melalui lagu-lagu Islam antara lain lagu berjudul “Jagalah" yang liriknya adalah :

Tanganmu yang dua jagalah Jangan sampai memukul yang salah

Kakimu yang dua jagalah Jangan sampai menendang yang salah.

Lisanmu yang satu jagalah, Jangan sampai mengucap yang salah 
Khusniyati Masykuroh. PENANAMAN NILAI KEISLAMAN PADA ANAK DHUAFA DI PAUD INSAN CERDAS KOTA BEKASI. Early Childhood Vol. 4 No. 1, Mei 2020

Karena kau diawasi oleh Allah Ta'ala.

\section{d. Pengenalan Huruf Hijaiyah dan} Surat Pendek. Sekolah melaksanakan pengenalan membaca Al-Quran yang dilaksanakan secara rutin dengan menggunakan metode tilawati. Setiap anak dibimbing secara klasikal dan personal oleh guru untuk mengenal huruf hijaiyah dan membaca Al-quran menggunakan metode Tilawati.

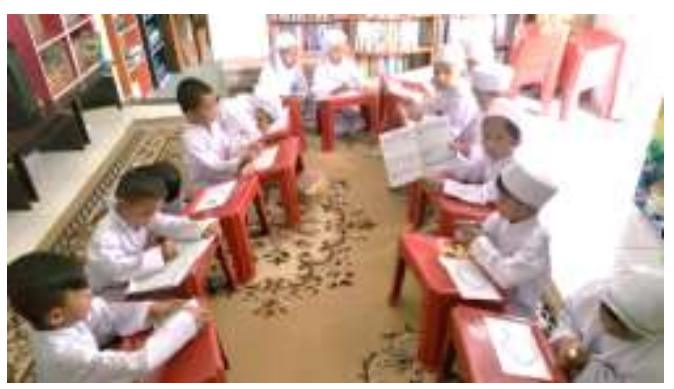

Gambar 4.

Pengenalan Membaca Al- Quran

2. Metode yang Digunakan Dalam

Penanaman Nilai-Nilai Keislaman.

Berdasarkan hasil observasi dan wawancara kepada Kepala Sekolah, guru, dan orang tua murid PAUD Insan Cerdas, metode yang digunakan dalam menanamkan nilai-nilai keislaman pada anak usia dini sudah sesuai dengan tahapan anak. alam melakukan penanaman nilai-nilai keislaman pada anak dhuafa di PAUD Insan Cerdas. Pada observasi dapat dilihat guru-guru melakukan pembelajaran yang menyenangkan dan kreatif, serta bervariasi sehingga anak tidak mudah bosan, bersemangat, dan antusias mengikuti pembelajaran.

Metode yang digunakan dalam menanamkan nilai-nilai keislaman di PAUD Insan Cerdas adalah metode berkisah, bermain, bernyanyi, pembiasaan, demonstrasi, praktek, tanya jawab, dan keteladanan.

\section{Hambatan dan Dukungan dalam}

\section{Penanaman Nilai Keislaman}

Berdasarkan hasil observasi dan wawancara, ditemukan bahwa hambatan penanaman nilai keislaman di PAUD Insan Cerdas adalah latar belakang orang tua yang berpendidikan rendah dan tingkat pengetahuan agama yang rendah, dimana masih kental dengan adat istiadat seperti mengirim sesaji dan menggantungkan sesaji di pohon.

Selain itu hambatan yang dihadapi adalah latar perekonomian keluarga yang rendah. Hal-hal tersebut berdampak pada pola asuh keluarga yang cenderung tradisional dan jauh dari nilai-nilai Islami, cara berkomunikasi yang negatif pada anak 
seperti berteriak, memarahi anak tidak pada tempatnya, dan tidak ada bimbingan agama di rumah.

Sedangkan dukungan yang sangat bermanfaat dalam menanamkan nilai -nilai keislaman datang dari Yayasan dan donatur yang tidak berhenti berusaha untuk mengajak orang tua dengan membuka kelas belajar keagamaan khusus orang tua murid dan alumni, melalui kelas Membaca Al Quran dan Majelis Taklim Insan Cerdas.

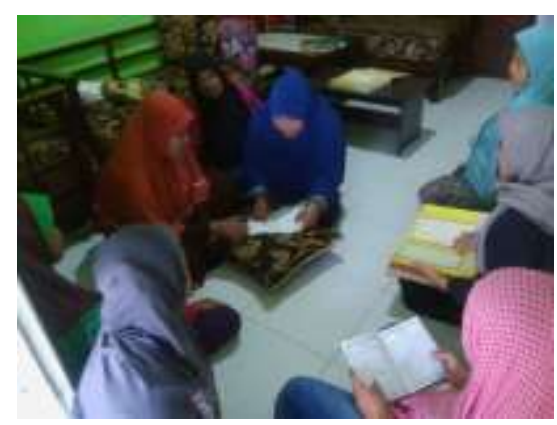

Gambar 5. Orangtua Belajar Baca Al-Quran

Kelas belajar keagamaan ini bertujuan untuk membangun kesadaran beragama pada orang tua, sehingga turut serta dalam menanamkan nilai-nilai keislaman pada anak di rumah.

\section{Dampak Penanaman Nilai-Nilai}

\section{Keislaman.}

Penanaman nilai keislaman pada anak dhuafa di PAUD Insan
Cerdas menunjukkan dampak yang positif dalam perkembangan anak. Hal ini ditunjukkan dalam data pencapaian perkembangan siswa PAUD Insan Cerdas kelompok usia 5-6 tahun yang disampaikan oleh guru, menunjukkan semua anak mencapai skala Berkembang Sesuai Harapan (BSB) dan Berkembang Sangat Baik (BSB) dalam semua komponen Aqidah, Praktek Ibadah, Akhlak, dan Pengenalan Bacaan dan Surat Pendek Alquran.

Hasil wawancara dengan orang tua juga menunjukkan perilaku anak di rumah, terbiasa mengucap dan menjawab salam, bicara santun dan berperilaku sopan terhadap orang tua, dan bersemangat saat melaksanakan praktek ibadah di rumah seperti : berwudhu dan sholat.

\section{SIMPULAN}

Berdasarkan uraian dan hasil penelitian, serta pembahasan yang telah dilakukan maka dapat disimpulkan bahwa :

1. Penanaman nilai-nilai keislaman pada anak dhuafa di PAUD Insan Cerdas melalui empat komponen utama yaitu pengenalan aqidah, praktek ibadah, akhlak, serta 
Khusniyati Masykuroh. PENANAMAN NILAI KEISLAMAN PADA ANAK DHUAFA DI PAUD INSAN

CERDAS KOTA BEKASI. Early Childhood Vol. 4 No. 1, Mei 2020

pengenalan membaca dan surat pendek Al-quran.

2. Metode penanaman nilai-nilai keislaman yang digunakan adalah berkisah, bernyanyi, bermain, pembiasaan, demonstrasi, praktek, dan tanya jawab.

3. Hambatan yang dihadapi dalam penanaman nilai-nilai keislaman adalah latar belakang orang tua murid yang semuanya adalah dhuafa berpendidikan rendah dengan tingkat pengetahuan agama yang rendah. Sedangkan untuk pendukungnya adalah Yayasan Insan Cerdas dan donatur yang peduli tidak hanya pada pendidikan anak melalui program kurikulum keislaman, namun juga memberikan pendidikan agama untuk orang tua supaya bisa bersinergi dalam menanamkan nilai keislaman di rumah dan di sekolah.

4. Dampak penanaman nilai keislaman pada anak dhuafa terlihat pada perubahan perilaku anak dalam mengenal Allah melalui ciptaannya, bersikap dan berkata baik, saling membantu dan menyayangi, mampu praktek gerakan ibadah seperti wudhu, sholat, doa, manasik haji, serta mengenal bacaan dan suratsurat pendek Al-quran.

\section{DAFTAR PUSTAKA}

Jasuri. (2015). Pembelajaran Pendidikan Agama Islam Pada Anak Usia Dini. Jurnal Madaniyah, VII, 16-31.

Miles, M. B., \& Huberman, A. M. (1994). Qualitative data analysis.pdf. Qualitative Data Analysis. https://doi.org/10.1007/s10071013-0700-5

Moleong, L. J. (2017). Metodologi Penelitian Kualitatif (Edisi Revisi). In PT. Remaja Rosda Karya.

Nurani, Y. (2013). Konsep Dasar Pendidikan Anak Usia Dini. Jakarta: Indeks.

Nurhayati, E. (2016). Penanaman Nilai Keislaman ( Studi Kasus di RA Al-Ishlah Bobos - Cirebon ). Awlady, 1-22.

Setiaji Raharjo. (2012). Penanaman Nilai-Nilai Agama Islam Pada Anak Usia Dini di Kelompok Bermain 'Aisyiah AL Husna II Pengasih, Kec. Pengasih, Kab. Kulonprogo.

Sugiyono. (2016). Memahami Penelitian Kualitatif. In Bandung: Alfabeta. 